GA-A15370

\title{
NONLINEAR DYNAMIC ANALYSIS OF PRISMATIC ELEMENTS FOR HIGH-TEMPERATURE GAS-COOLED REACTOR CORES
}

by

H. D. SHATOFF, R. W. THOMPSON, and T. H. LEE

JUNE 1979 


\section{DISCLAIMER}

This report was prepared as an account of work sponsored by an agency of the United States Government. Neither the United States Government nor any agency Thereof, nor any of their employees, makes any warranty, express or implied, or assumes any legal liability or responsibility for the accuracy, completeness, or usefulness of any information, apparatus, product, or process disclosed, or represents that its use would not infringe privately owned rights. Reference herein to any specific commercial product, process, or service by trade name, trademark, manufacturer, or otherwise does not necessarily constitute or imply its endorsement, recommendation, or favoring by the United States Government or any agency thereof. The views and opinions of authors expressed herein do not necessarily state or reflect those of the United States Government or any agency thereof. 


\section{DISCLAIMER}

Portions of this document may be illegible in electronic image products. Images are produced from the best available original document. 
GA-A15370

\section{NONLINEAR DYNAMIC ANALYSIS OF PRISMATIC ELEMENTS FOR HIGH-TEMPERATURE GAS-COOLED REACTOR CORES}

by

H. D. SHATOFF, R. W. THOMPSON, and T. H. LEE

This is a preprint of a paper to be presented at the SMiRT-5 Conference in Berlin, West Germany, August 13-17, 1979.

Work supported by

Department of Energy Contract DE-AT03-76ET35300
NOTICE -

This prepared as an account to work United States'y United States Government. Neither the Eneroy, nor any of their employees, nor any of their contractors, subcontractors, or their entoyy, makes

any warranty, express or implied, or assurnes any legat liability or rexpentive

ar usefuness of any inform infringe privately owned rights.

GENERAL ATOMIC PROJECT 6400 JUNE 1979

\section{GENERAL ATOMIC COMPANY}


CONTENTS

ABSTRACT . . . . . . . . . . . . . . . . . . . . . 1

1. INTRODUCTION . . . . . . . . . . . . . . . . . 1

2. CORE SEISMIC COMPUTER PROGRAMS . . . . . . . . . . . . . 4

2.1. CRUNCH-1D ...................... 4

2.2. CRUNCH-2D ................... 8

2.3. $\mathrm{MCOCO}$. . . . . . . . . . . . . . . 10

3. IMPACT MODELS ....................... . . 10

3.1. Collision Impact Mechanisms . . . . . . . . . . . 10

3.2. Model Specification . . . . . . . . . . . . . . 22

4. COMPARISON OF FREQUENCY RESPONSE . . . . . . . . . . . . . 25

4.1. Sweep Rate... . . . . . . . . . . . . 25

4.2. Frequency Response . . . . . . . . . . . . . . 28

4.3. MCOCO Core Motion Characteristics . . . . . . . . . 28

5. FUTURE DEVELOPMENT . . . . . . . . . . . . . . 28

REFERENCES ........................ 32

FIGURES

1. HTGR configuration .... . . . . . . . . . . . . 2

2. Plan view of HTGR core . . . . . . . . . . . . . . 3

3. CRUNCH 10 computer model elements . . . . . . . . . . 5

4. CRUNCH-2D computer model elements . . . . . . . . . . 6

5. MCOCO computer model elements . . . . . . . . . . . . 7

6. CRUNCH-1D core model .................. . . 9

7. MCOCO full array model . . . . . . . . . . . . . . 11

8. Fifth-scale pendulum collision test rig ... . . . . . . . 12

9. Experimental coefficient of restitution versus impact velocity--full-scale elements . . . . . . . . . 13 
10. Experimental contact time versus impact velocity--fullscale elements................. 14

11. CRUNCH-1D hybrid impact mechanism .......... 17

12. Maxwell impact mechanism .............. 18

13. Voigt impact mechanism ............... 19

14. Standard linear solid impact mechanism ......... 20

15. Voigt impact mechanism with nonlinear spring ........ 21

16. CRUNCH-2D e lement . . . . . . . . . . . . 23

17. MCOCO model . . . . . . . . . . . . . . . . . 24

18. Rocking angle time history............ . . 26

19. Resonance characteristics ............ 27

20. Effect of sinusoidal sweep rate ............ 29

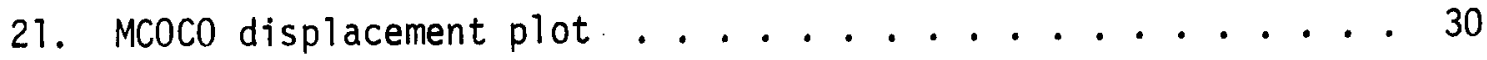


NONLINEAR DYNAMIC ANALYSIS OF PRISMATIC ELEMENTS

FOR HIGH-TEMPERATURE GAS-COOLED REACTOR CORES*

H. D. Shatoff, R. W. Thompson, and T. H. Lee

General Atomic Company, P. 0. Box 81608, San Diego, California 92138, USA

The high-temperature gas-cooled reactor (HTGR) core consists of several thousand prismatic graphite fuel elements arranged in columns within a prestressed concrete vesse1. A major research and development effort was initiated in 1970 at General Atomic Company to study the dynamic response of the HTGR core arrangement to seismic excitation.

This paper presents a discussion of the history and some of the results of this effort with respect to the advances made in the development of analytical methods. The computer programs developed to perform the analys is are described, along with certain techniques and the modeling required to utilize them. The purpose of this paper is to describe the nonlinear dynamic analysis techniques employed to analyze the HTGR core. Correlation of the codes is beyond the scope of the paper and will be discussed in subsequent publications.

Each fuel column in the HTGR core is composed of stacked elements doweled together to ensure alignment of the coolant channels. Gaps exist between columns allowing the elements to impact during a seismic disturbance. Analys is of this type of structure by standard structural dynamics techniques is not possible since both nonlinearities and discontinuities exist. One- and two-dimensional models of the three-dimensional core have been developed with explicit time integration methods. Various methods to treat the impact between elements are discussed.

Three computer codes were developed. CRUNCH-1D models a one-dimensional horizontal strip through the core; CRUNCH-2D, a two-dimensional horizontal planar section; and MCOCO, a two-dimensional vertical planar section. The dynamic characteristics of these three representations of the full core structure are compared and the methods evaluated in the text. Plans for additional development and work to improve the techniques are also discussed.

\section{INTRODUCTION}

The core of General Atomic's large HTGR (Fig. 1) consists of more than 8000 graphite elements arranged in columns within a prestressed concrete reactor vessel (PCRV). Each fuel column may contain 14 or more elements. A plan view of the core shows that elements are either hexagonal or multifaceted prisms (see Fig. 2). Elements in each column are constrained in the horizontal direction by dowels which allow unconstrained rotation and vertical translation. Gaps also may exist between dowels and their sockets and between columns. A comprehensive research and development program was undertaken at General Atomic in 1970 to develop means to analyze the HTGR core for seismic loads $[1,2,3]$.

\footnotetext{
ॠWork supported by U.S. Department of Energy under Contract EY-76-C-03-0167, Project Agreement 65.
} 


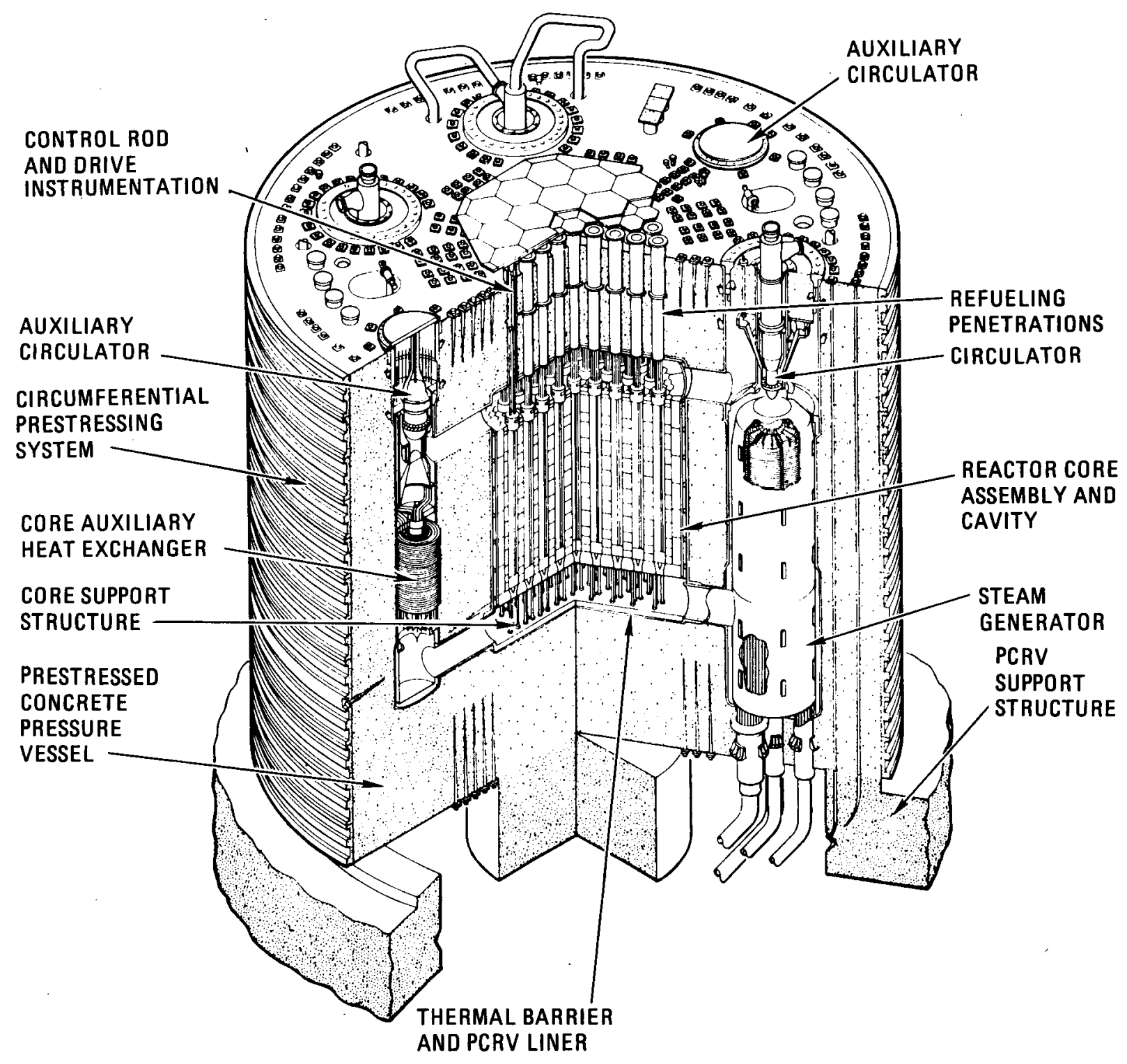

Fig. 1. HTGR configuration 


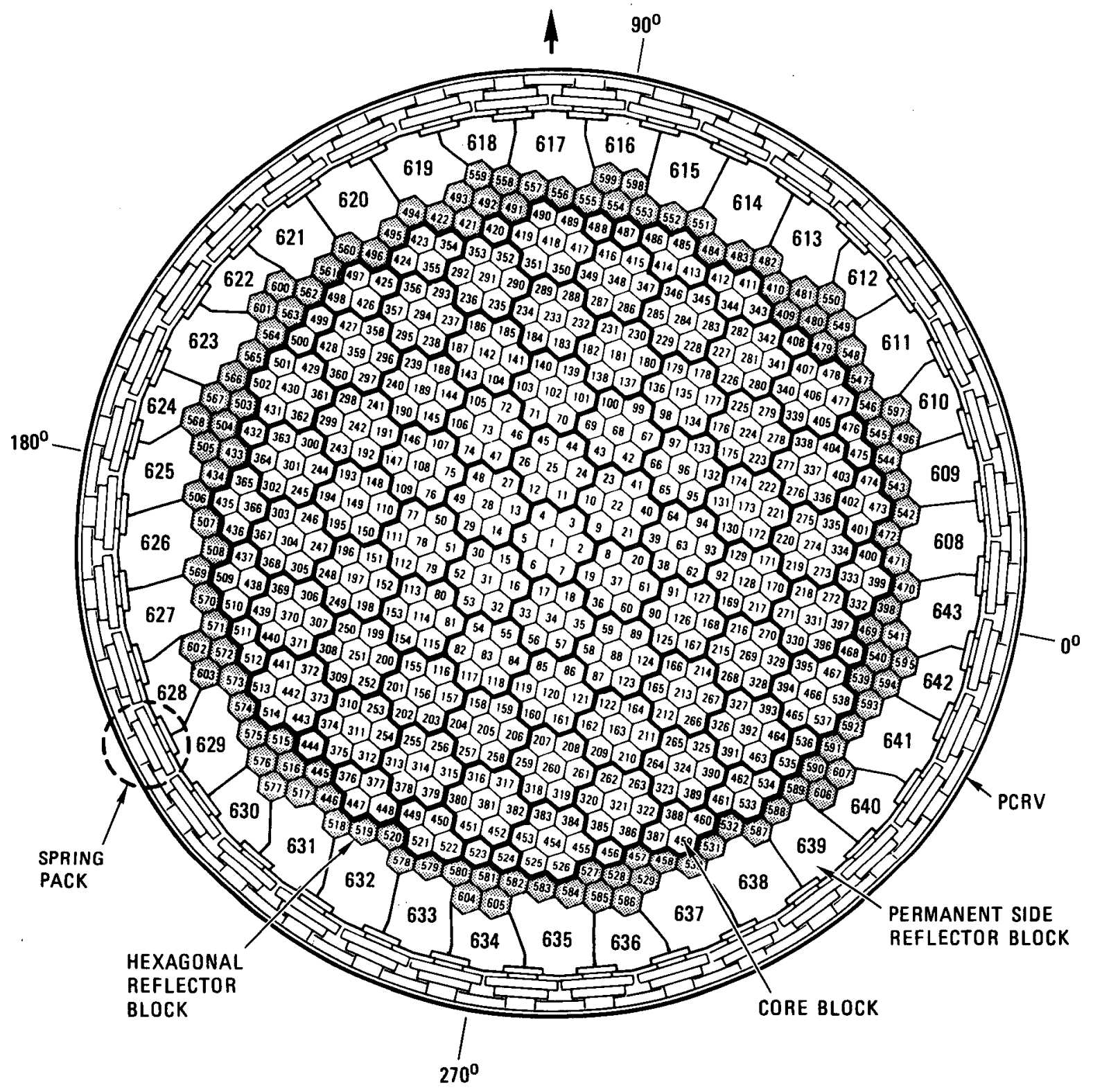

Fig. 2. Plan view of HTGR core 
It was decided that specialized computer analysis techniques were necessary for this purpose.

The first core model consisted of a single, solid element with the total cross core gap between the element and boundary. This model was useful only to provide conservative boundary loads. It could produce no internal core data. The next stage of development was to model each core element as a rigid body with surface "impact mechanisms." The following impact mechanisms were investigated: impulse momentum, viscoelastic, nonlinear spring-damper, and hybrid impulse and spring systems. A viscoelastic model was selected for incorporation into the computer codes. When the program began, it was recognized that the most complete core representation geometrically would be a three-dimensional model with each of the 8000 or more elements represented with six degrees of freedom. However, the excessive costs and computational problems associated with a computer analysis of this magnitude quickly removed this as an option. This was subsequently justified from test results obtained with a $1 / 5$ scale three-dimensional core model [2]. These tests showed a predominately lumped core motion and insignificant structural coupling in orthogonal directions. This implied that simpler one- and two-dimensional models would be adequate in performing the seismic analysis.

The first core seismic analysis computer program developed was CRUNCH-1D [4]. This code models a one-dimensional array of elements across the core diameter in a direction normal to the sides of a hexagonal fuel element (see Fig. 3). The two-dimensional codes developed were CRUNCH-2D [5] and MCOCO [6]. CRUNCH-2D models a horizontal array as depicted in Fig. 4; MCOCO models a vertical array in the core as shown in Fig. 5.

2. CORE SEISMIC COMPUTER PROGRAMS

\subsection{CRUNCH-1D}

CRUNCH-1D was developed as an inexpensive tool to analyze the response of the core during seismic disturbances. It models the core as a horizontal array of elements having one degree of freedom in the horizontal direction. Each 


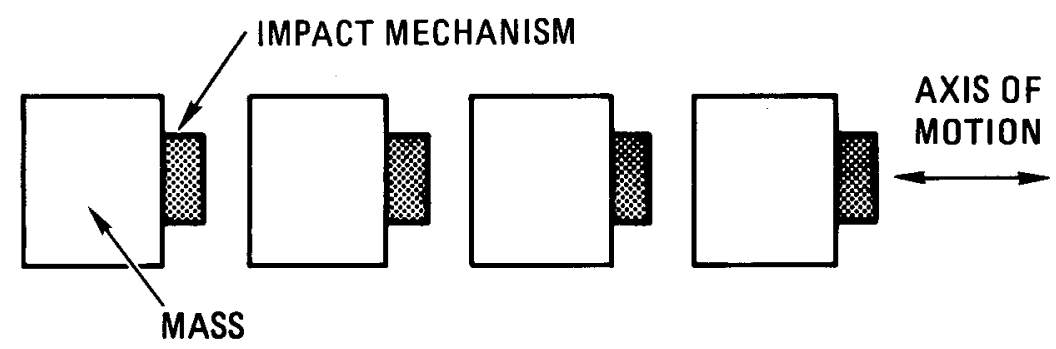

Fig. 3. CRUNCH-1D computer model elements 


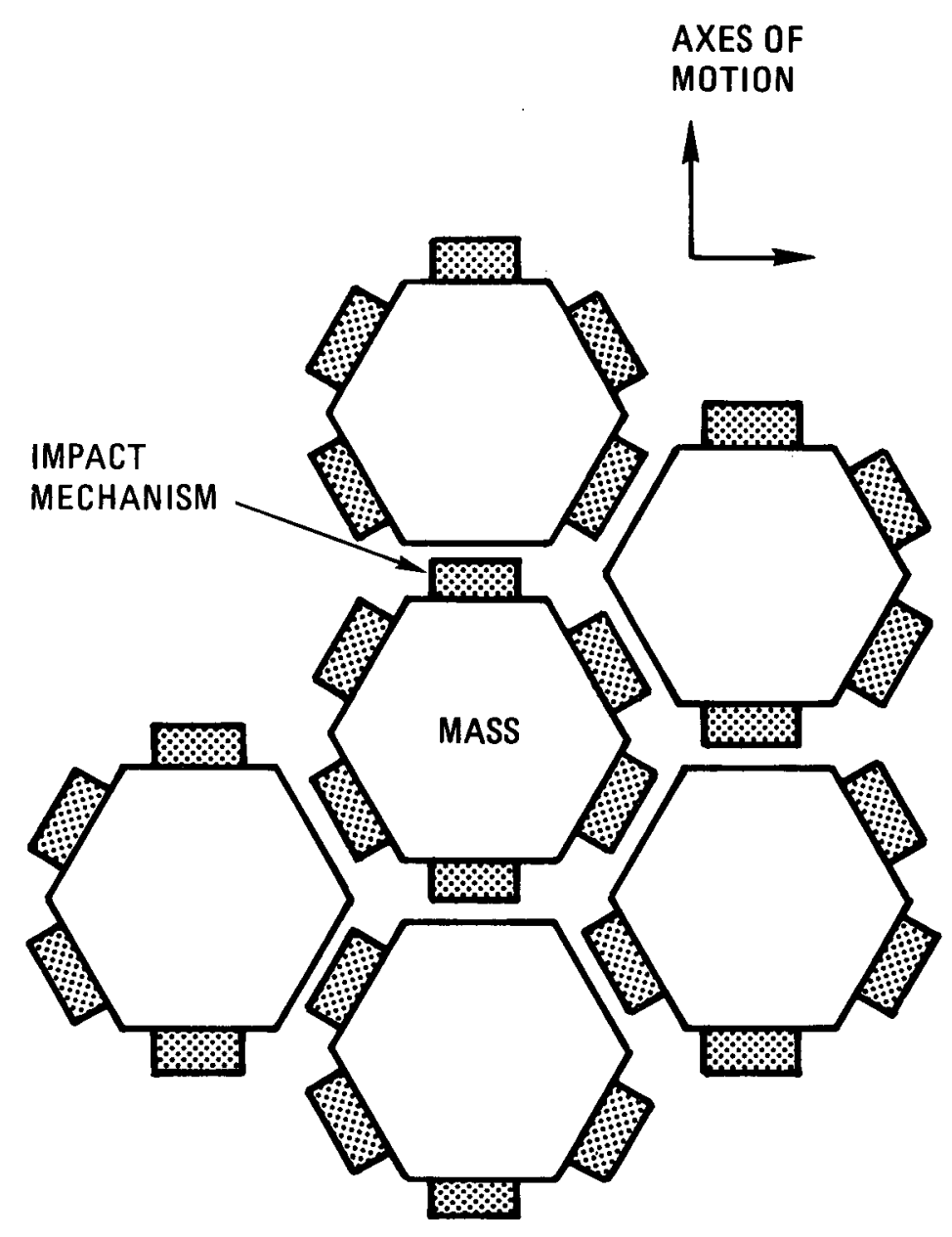

Fig. 4. CRUNCH-2D computer model elements 


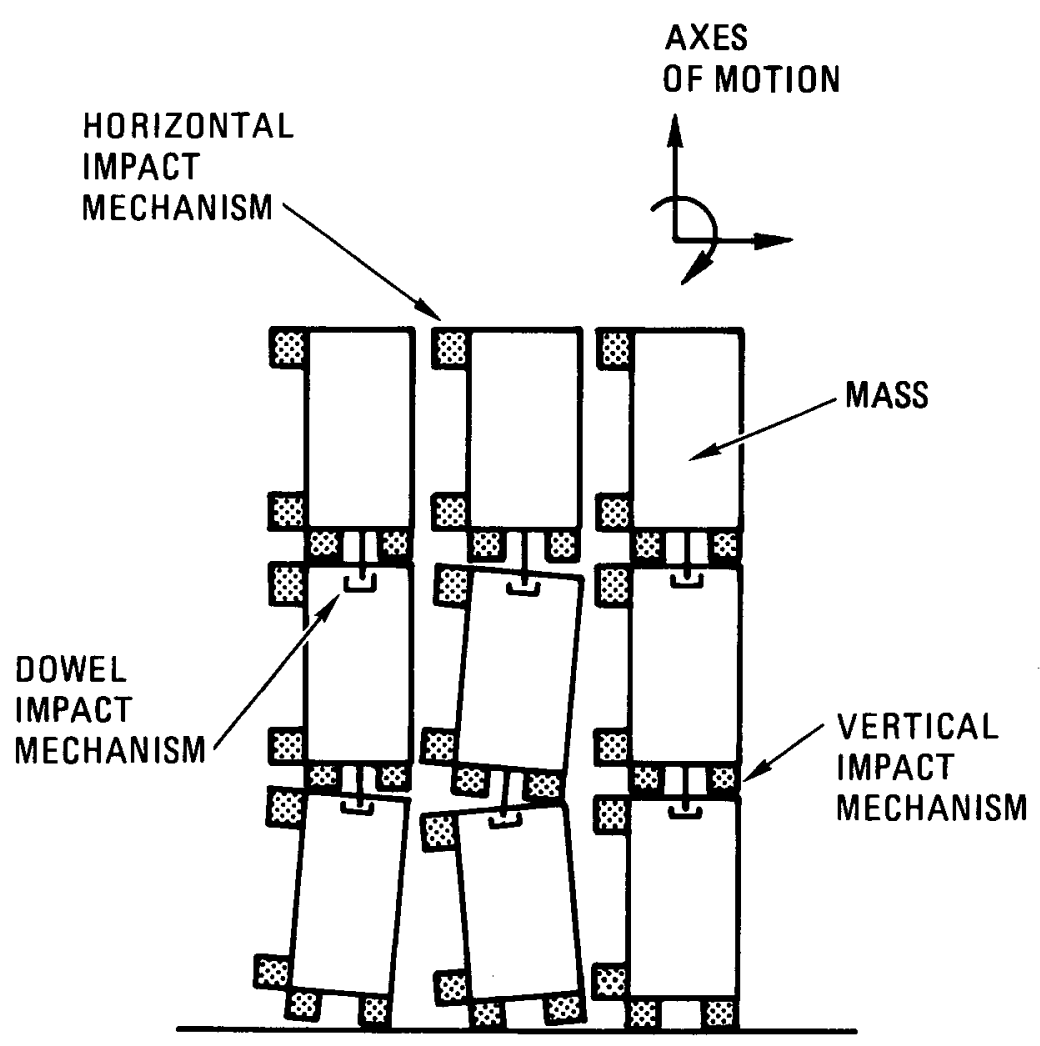

Fig. 5. MCOCO computer model elements 
element in the model is a single mass representing a column or group of columns of the actual core. Each mass is attached to the core support floor by a column spring. Collisions between elements occur at the impact mechanisms. Gaps may have to be traversed prior to contact. The entire system is contained within the PCRV (boundary), and spring packs separate the boundary and reflector elements. The core support floor is incorporated as a single mass. Excitation is provided by the PCRV acceleration. A typical CRUNCH-1D model is presented in Fig. 6. Dynamic response of the system is determined by computing the acceleration of each element. Accelerations are then integrated to yield velocities and displacements. A central difference or Runge-Kutta integration method is used in all of the codes.

\section{$2.2 \mathrm{CRUNCH}-2 \mathrm{D}$}

CRUNCH-2D models a two-dimensional horizontal HTGR core plane. It is capable of analyzing the full horizontal planar layer of the core as shown in Fig. 2. This computer program was developed as a major tool for studying the seismic response of the core considering in-plane two-dimensional and two axis input effects. The code has been generalized to handle a wide range of core, reflector, and boundary elements coupled with one- or two-axis horizontal excitation. Each element mass represents one column of the core and is attached to the core support floor by column springs and dampers. The core support floor in $\mathrm{CRUNCH}-2 \mathrm{D}$ is represented by a single mass (the same as CRUNCH-1D). The hexagonal elements are surrounded by irregular shaped permanent side reflectors. Lateral core loads are transmitted from permanent side reflectors into the PCRV liner through the surrounding spring packs. The spring packs react to both radial and tangential loads. Seismic acceleration can be applied to the boundary along one or two perpendicular horizontal acceleration axes. All elements are assumed to have translational motion only, and rotation about a vertical axis is not considered. Element forces are assumed to react perpendicular to block faces and friction is ignored. The line of application of each force passes through the element center of gravity so that no moment is produced. 


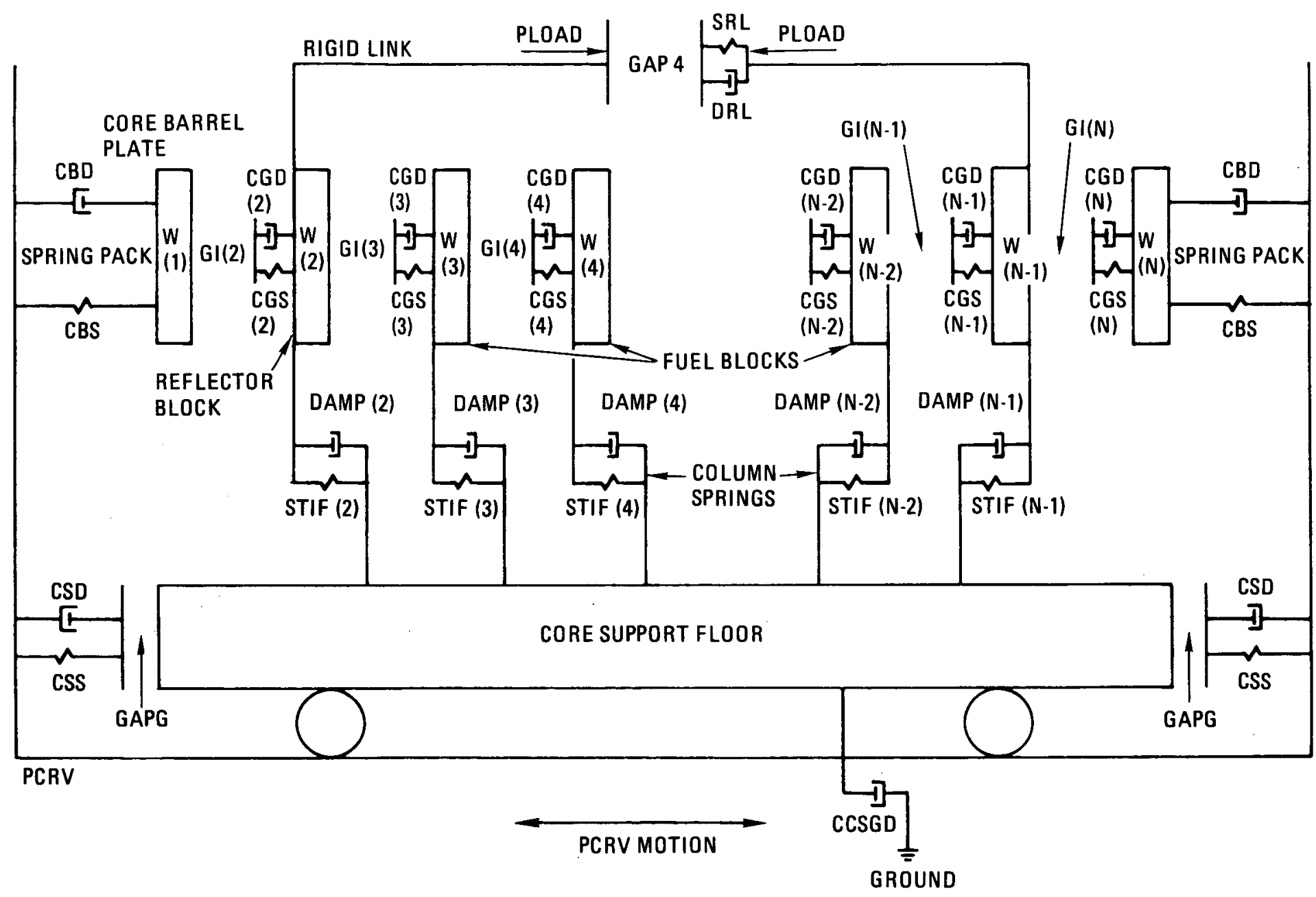

Fig. 6. CRUNCH-ID core modeI 


\subsection{MCOCO}

MCOCO is a two-dimensional computer program developed for analyzing the motions of core elements in a vertical plane. The model consists of a series of vertical columns atop a row of core support elements. Included in the model are columns of fuel, hexagonal reflector, permanent reflector, and side shield elements. Each column is formed by a series of stacked elements constrained by dowels which restrict the relative horizontal motion but allow vertical translation and rocking. Fuel columns may be separated by gaps and may interact with adjacent columns or the boundary structure through impacts.

Elements in columns may be arranged in either a staggered or nonstaggered pattern. The core support floor is supported by posts. In the typical fullarray MCOCO model shown in Fig. 7 , each element has three degrees of freedom: horizontal and vertical translation and in-plane rotation. Rigid-body displacements of individual elements are utilized as coordinate variables. Surface flexibility is considered by the use of the discrete springs. When gaps are closed, impact forces (and resultant moments) are produced. The equations of motion are solved by numerical integration using explicit methods.

\section{IMPACT MODELS}

\subsection{Collision Impact Mechanisms}

The impact mechanisms for hexagonal graphite elements have been developed from test results for collisions between two elements. Several different tests were performed [7]. One, the 1/5-scale pendulum test, is pictured in Fig. 8. Measured results were coefficients of restitution and contact times. The coefficient of restitution is a measure of the energy absorption associated with impact. Contact time $\left(t_{c}\right)$ is an indicator of the relative "dynamic stiffness"of the element. Reproducing the coefficient of restitution and contact time shown on Figs. 9 and 10 was established as a goal for initial computer modeling. Several models used in the impact mechanisms are discussed in the following paragraphs. 


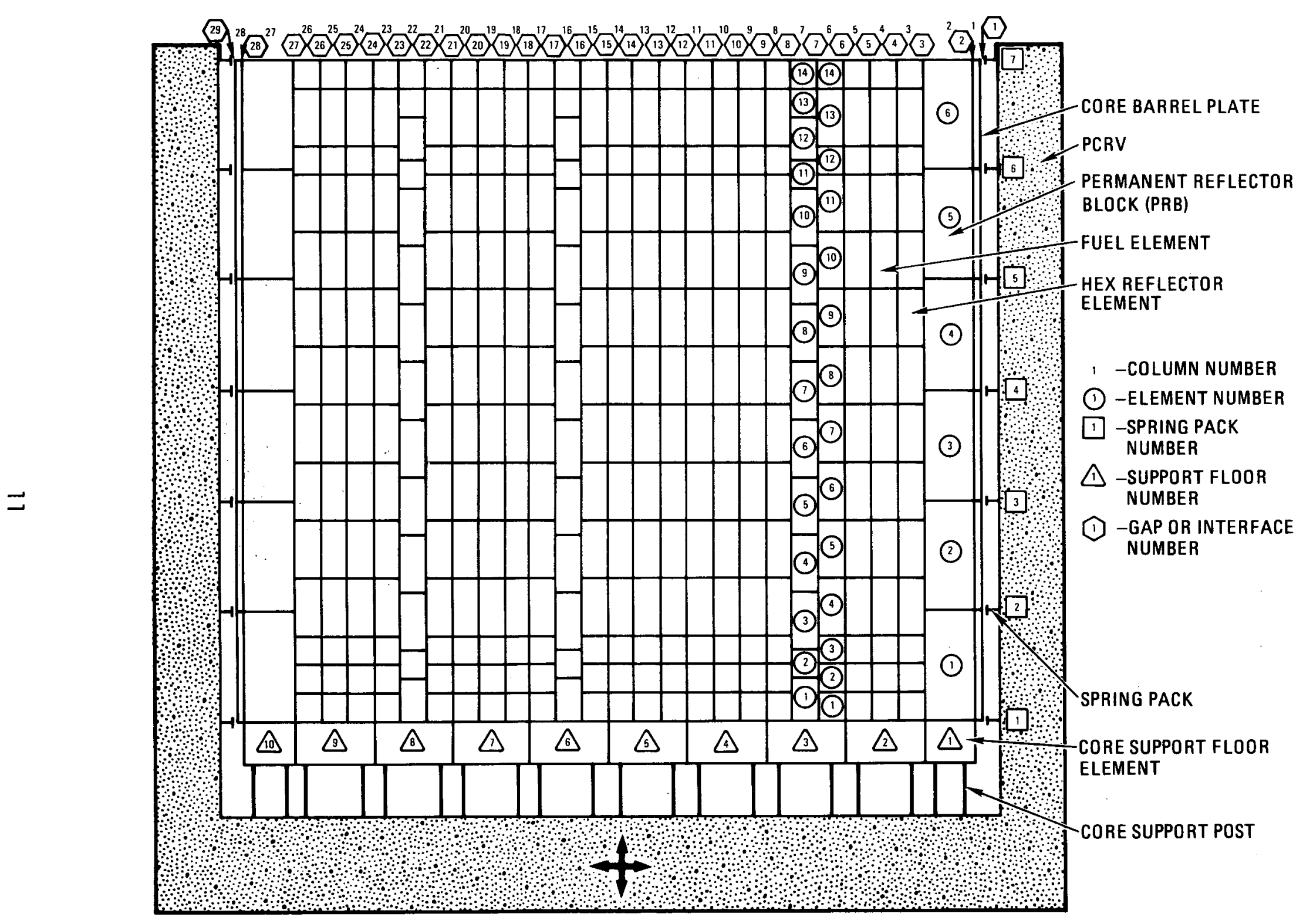

Fig. 7. MCOCO full array model 


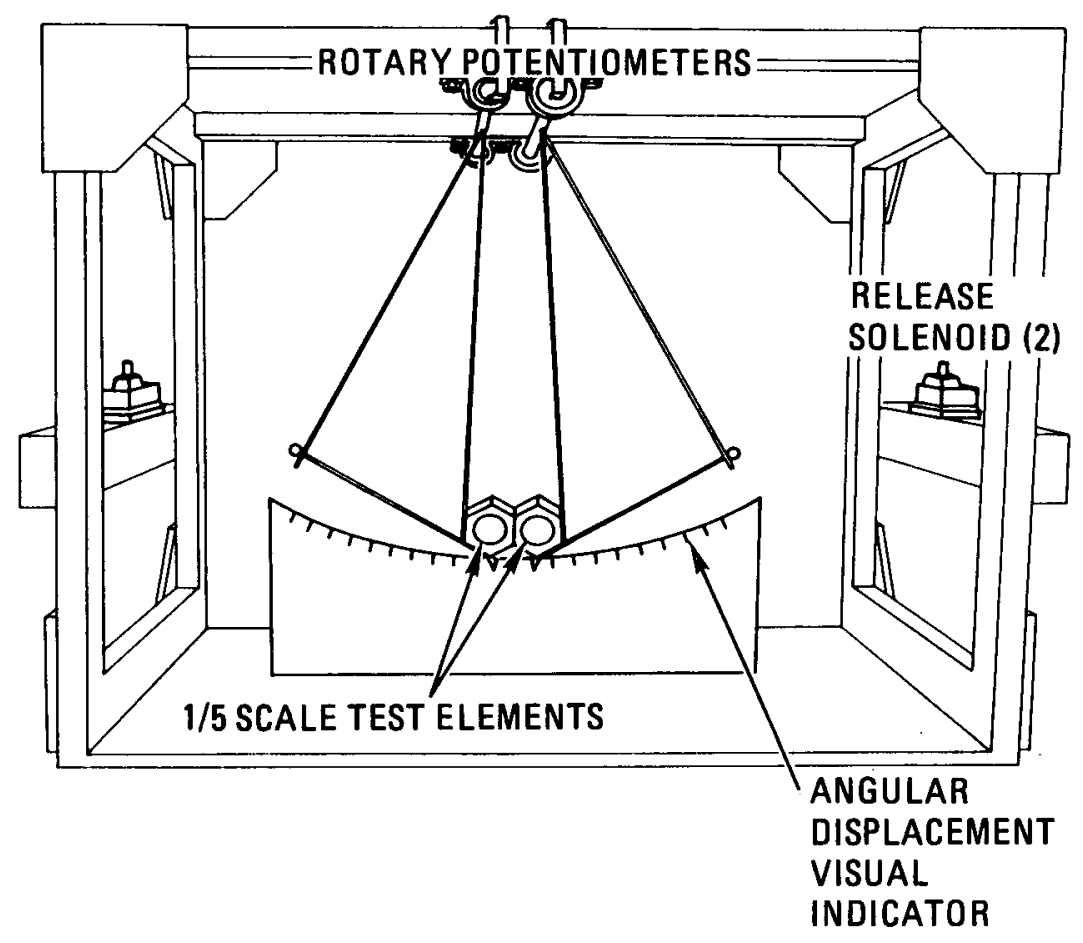

Fig. 8. Fifth-scale pendulum collision test rig 


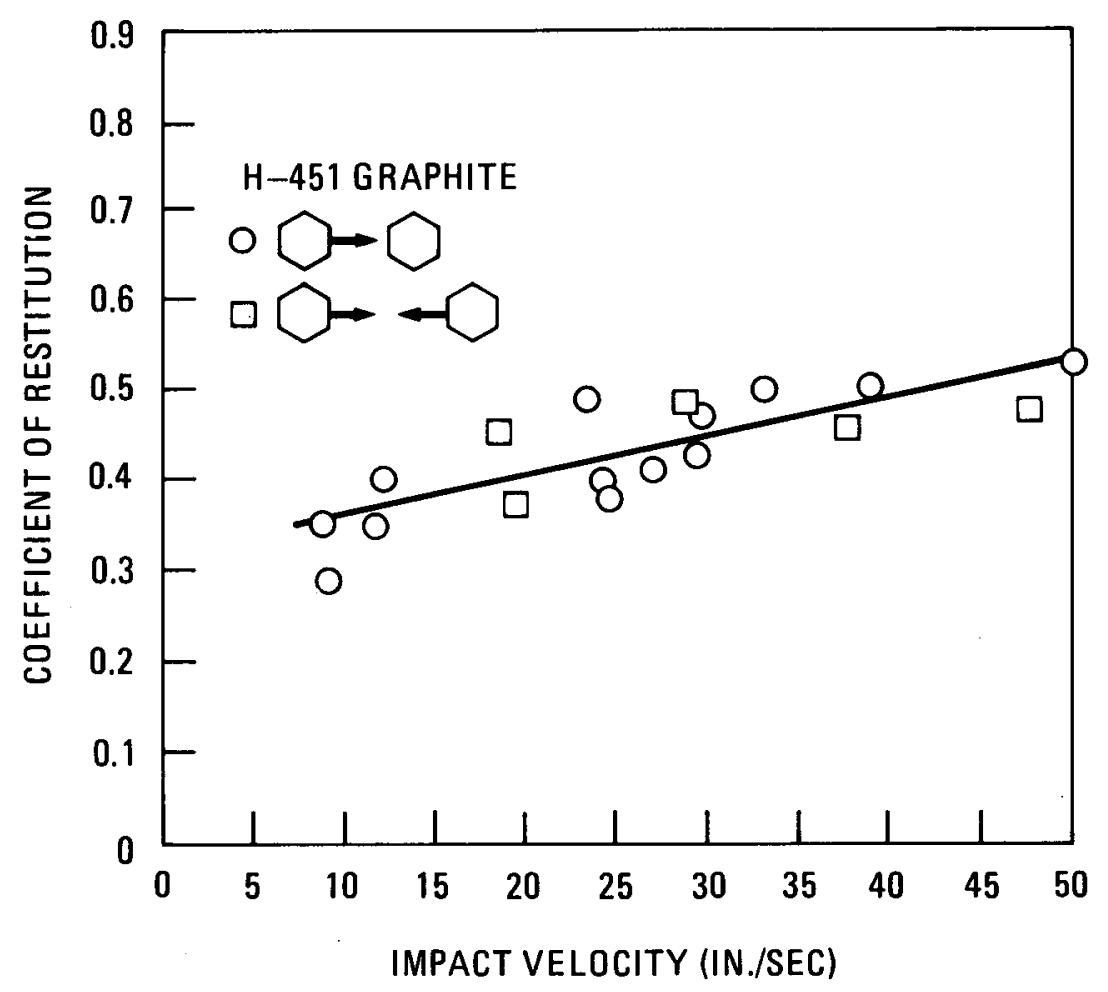

Fig. 9. Experimental coefficient of restitution versus impact velocity-full-scale elements 


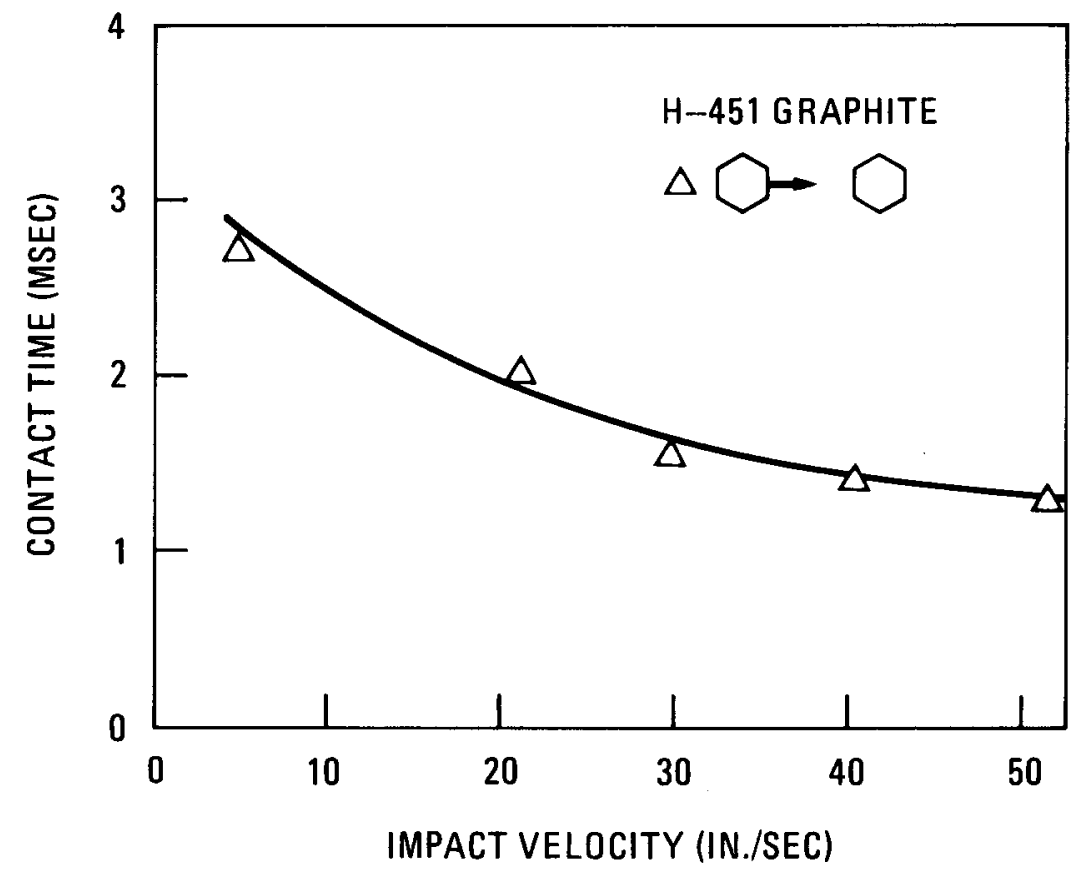

Fig. 10. Experimental contact time versus impact velocity--full-scale elements 
The impulse-momentum impact model computes velocities of two impacting elements according to the laws of conservation of momentum. Initially, this system appeared to have the advantages of flexibility and low cost. The coefficient of restitution could easily be made a function of velocity and adjusted to match tests. The change of velocity is a function of initial velocity, mass and coefficient of restitution. Impulse-momentum equations for the final velocity are

$$
\begin{aligned}
& v_{f_{A}}=\frac{\left[v_{i_{A}}\left(m_{A}-c R \cdot m_{B}\right)+v_{i_{B}}\left(m_{B}+C R \cdot m_{B}\right)\right]}{\left(m_{A}+m_{B}\right)} \\
& v_{f_{B}}=\frac{\left[v_{A}\left(m_{A}+C R \cdot m_{A}\right)+v_{i_{B}}\left(m_{B}-C R \cdot m_{A}\right)\right]}{\left(m_{A}+m_{B}\right)}
\end{aligned}
$$

where

$$
\begin{aligned}
& v_{f_{A, B}}=\text { the final velocity of element } A, B, \\
& v_{i_{A, B}}=\text { the initial velocity of element } A, B, \\
& m_{A, B}=\text { the mass of element } A, B .
\end{aligned}
$$

The velocity change occurs instantaneously. In actuality, however, the change in velocity requires finite time. This, in itself, does not introduce significant error in an analysis of a small number of elements with relatively large gaps between them since the impact time is small compared to the time of free motion. This method worked quite well for a small number of elements in an array with only internal impacts. Computational time relative to the spring damper system was lower by an order of magnitude. A more complex model of the full core, however, consists of a larger number of elements. Also to be considered are reflector elements, spring packs, and column restraints on each element. Problems were encountered when attemps were made to incorporate static loads and column springs and dampers with the impulse-momentum method. When elements were in contact, a continuous set of collisions occurred without a time change. This would not allow column spring deflections, and the analysis broke down. As a result, the hybrid impact mechanism was developed. 
The hybrid model is a low-stiffness spring coupled to an impulse-momentum impact mechanism as shown in Fig. 11. The interblock spring reacts from contact up to a deflection $\delta$. At this point, the impulse model takes over and the velocities of the two masses are changed according to impulse-momentum equations. Spring rates used are approximately $10 \%$ to $20 \%$ of those necessary to provide the measured contact time. The computational time savings relative to the spring-damper model is one-half to two thirds.

Several spring damper models were considered concurrently with the study of the impulse-momentum impact mechanism. It was recognized that run times for this model would be an order of magnitude larger than impulse-momentum methods, but that results should be more accurate and repeatable. Some specific impact models investigated are shown in Figs. 12 to 15 and 1 isted below:
a. Maxwel1.
b. Voigt.
c. Standard linear solid (SLS).
d. Voigt with nonlinear spring.

Each of these models was considered as to its ability to reproduce experimental values of coefficient of restitution and contact time. Only model d, above, is nonlinear.

The Maxwell model was rejected because it did not return under static loads. Although the Voigt model alleviated this problem, it had the disadvantage of a force discontinuity at initial impact. The SLS was then considered in order to alleviate this discontinuity. However, coefficients of restitution and contact time do not vary with velocity for the linear models. A more complex model (Voigt with a nonlinear spring) was then developed in order to match the test data. It was concluded that the overall dynamic response characteristics were more important than characteristics of individual elements. The Voigt model provided this as well as any of the more complex systems and was selected for incorporation into the codes. 


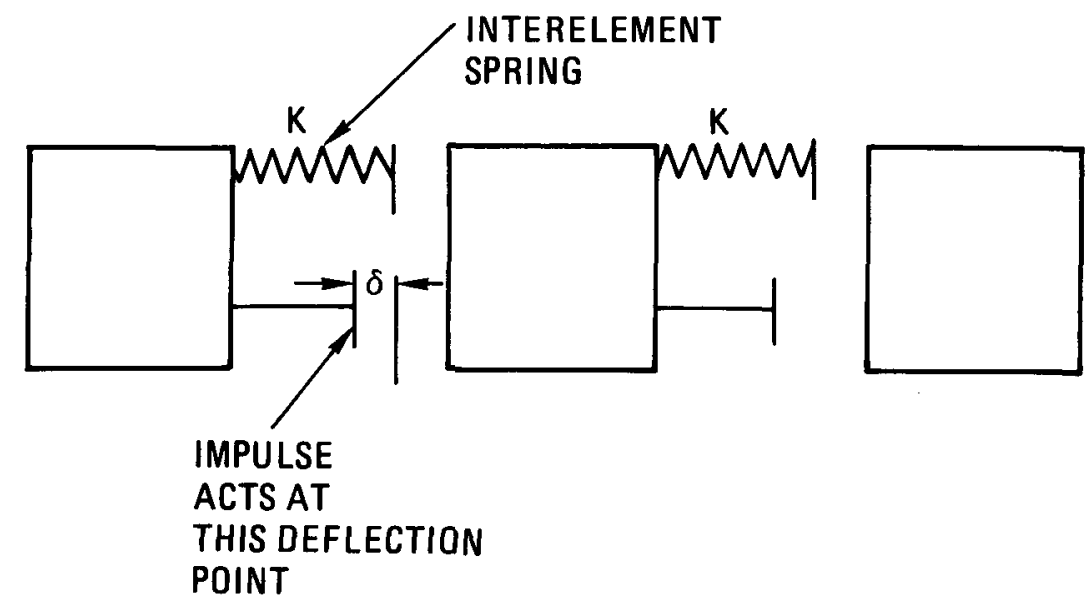

Fig. 11. CRUNCH-1D hybrid impact mechanism 


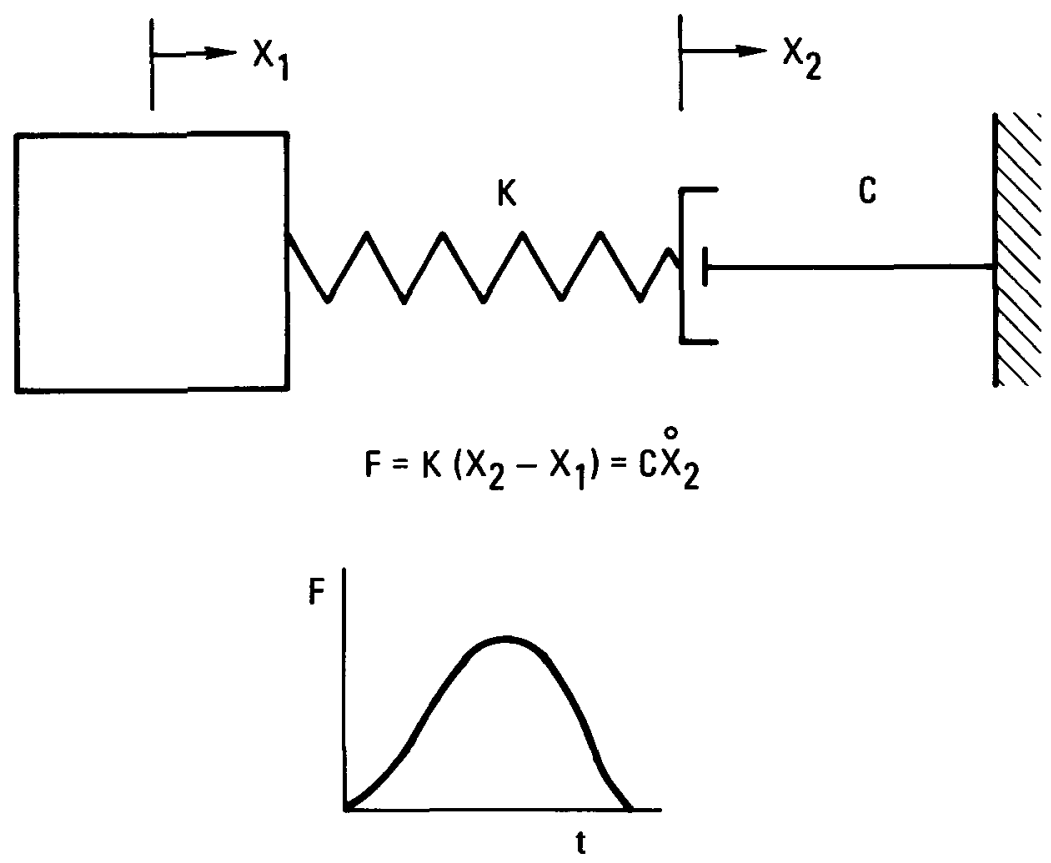

Fig. 12. Maxwell impact mechanism 


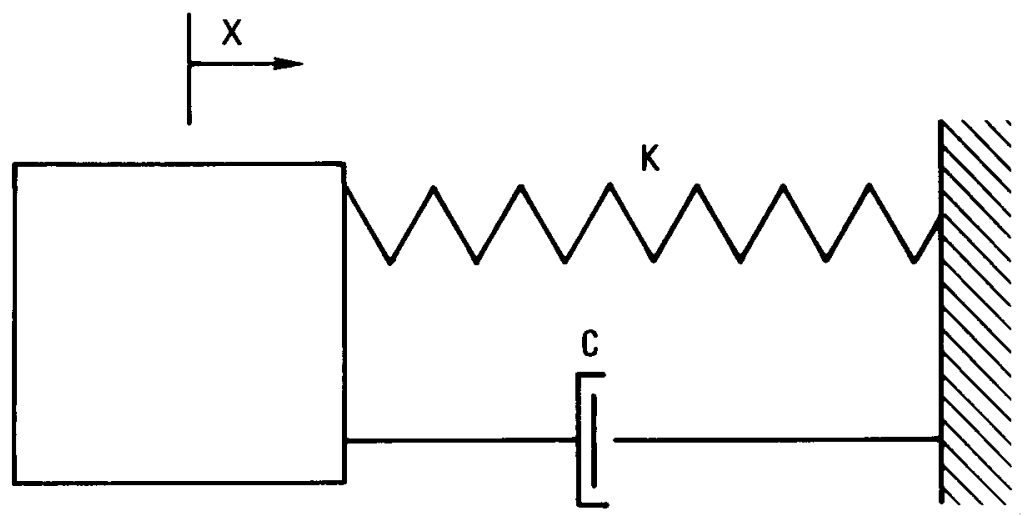

$$
F=K X+C \dot{X}
$$

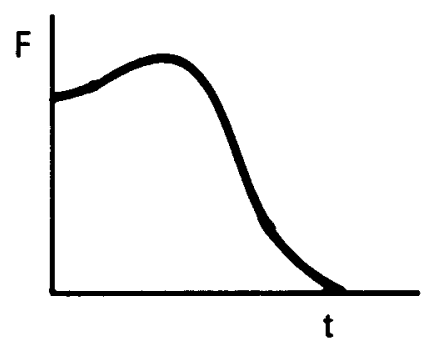

Fig. 13. Voigt impact mechanism

19 


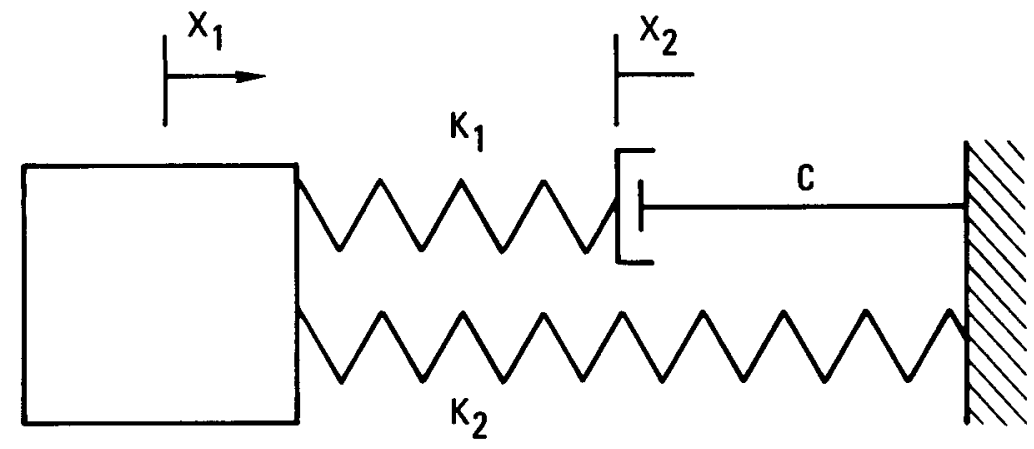

$$
\begin{aligned}
F= & k_{2} x_{1}+k_{1}\left(x_{2}-x_{1}\right) \\
& k_{1}\left(x_{2}-x_{1}\right)=c \dot{x}_{2}
\end{aligned}
$$

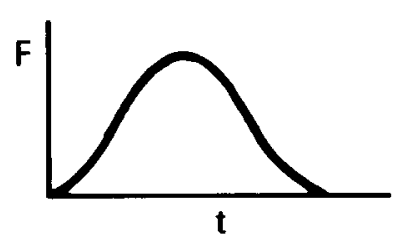

Fig. 14. Standard linear solid impact mechanism 


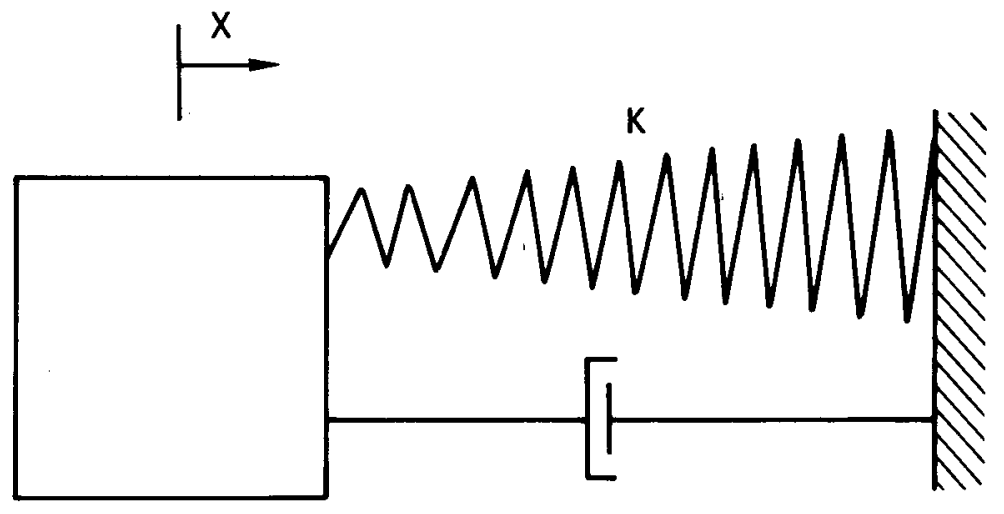

$F=k X^{a}|X|+C \dot{X}$

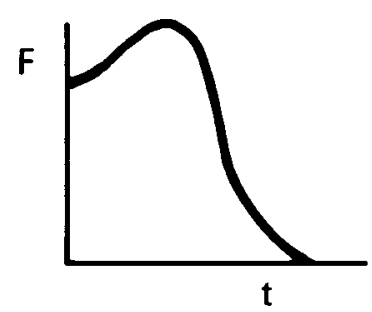

Fig. 15. Voigt impact mechanism with nonlinear spring 


\subsection{Model Specification}

As stated in Section 3.1, the Voigt model produces coefficients of restitution and contact time which do not vary with the impact velocity. For the Voigt system, the following expressions can be developed

$$
\begin{aligned}
& t_{c}=\pi \sqrt{\frac{M_{e}}{k}}, \\
& C R=e^{(-\pi C) / \sqrt{4 K M_{e}-C^{2}},} \\
& M_{e}=\frac{m_{A} m_{B}}{m_{A}+m_{B}},
\end{aligned}
$$

where $\quad t_{c}=$ time that two masses are in contact,

$$
\begin{aligned}
C R & =\text { coefficient of restitution, } \\
M_{e} & =\text { effective mass of the two elements, } \\
m_{A}, m_{B} & =\text { mass of elements } A \text { and } B, \\
K & =\text { interblock spring rate, selected to reproduce } t_{C}(1 b / i n .), \\
C & =\text { interblock viscous damper rate }(1 b-s e c / i n .) .
\end{aligned}
$$

Viscous damping was calculated from Eq. 1 using a coefficient of restitution of 0.4. Test data for full scale fuel elements is shown in Figs. 9 and 10 [7]. The value of 0.4 is an average coefficient of restitution from Fig. 9. For full-scale 260 lb hexagonal graphite elements, a contact time of $2.0 \mathrm{msec}$ was selected (Fig. 10). These values established the properties for the full scale horizontal impact mechanism. The $1 / 5$ scale model utilized a coefficient of restitution of 0.36 and contact time of $0.4 \mathrm{msec}$ [7]. CRUNCH-2D utilized the same properties on each of the six impact faces (see Fig. 16).

The MCOCO core model, on the other hand, is more complex. Rocking characteristics of the columns are important. The rocking phenomenon was best simulated by using one Voigt impact mechanism at each vertical corner of the element (see Fig. 17). Corner impact mechanisms were used on both horizontal and vertical element faces. The horizontal impact characteristics were kept consistent with the CRUNCH codes by utilizing the same values of spring 


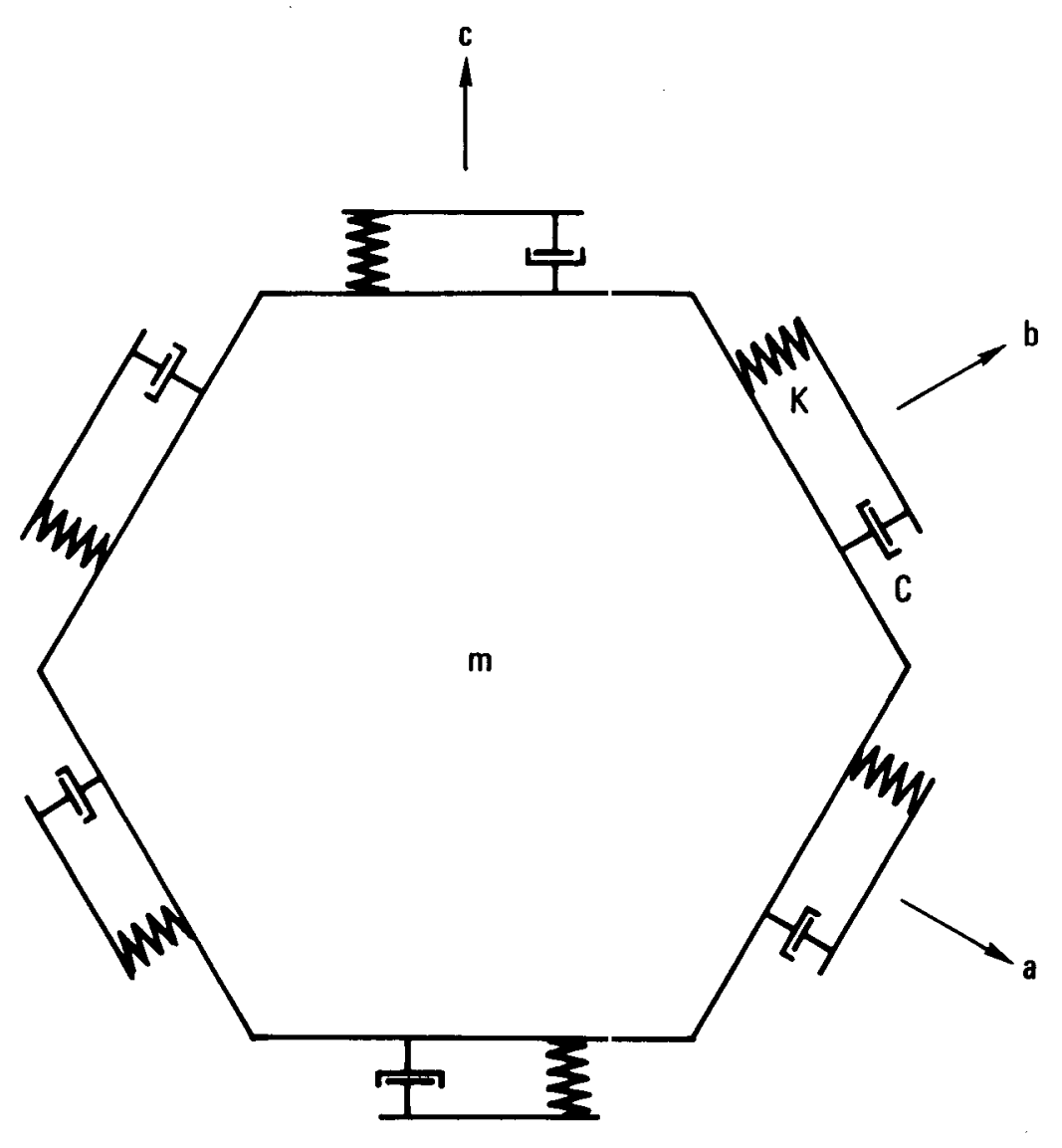

Fig. 16. CRUNCH-2D e lement 


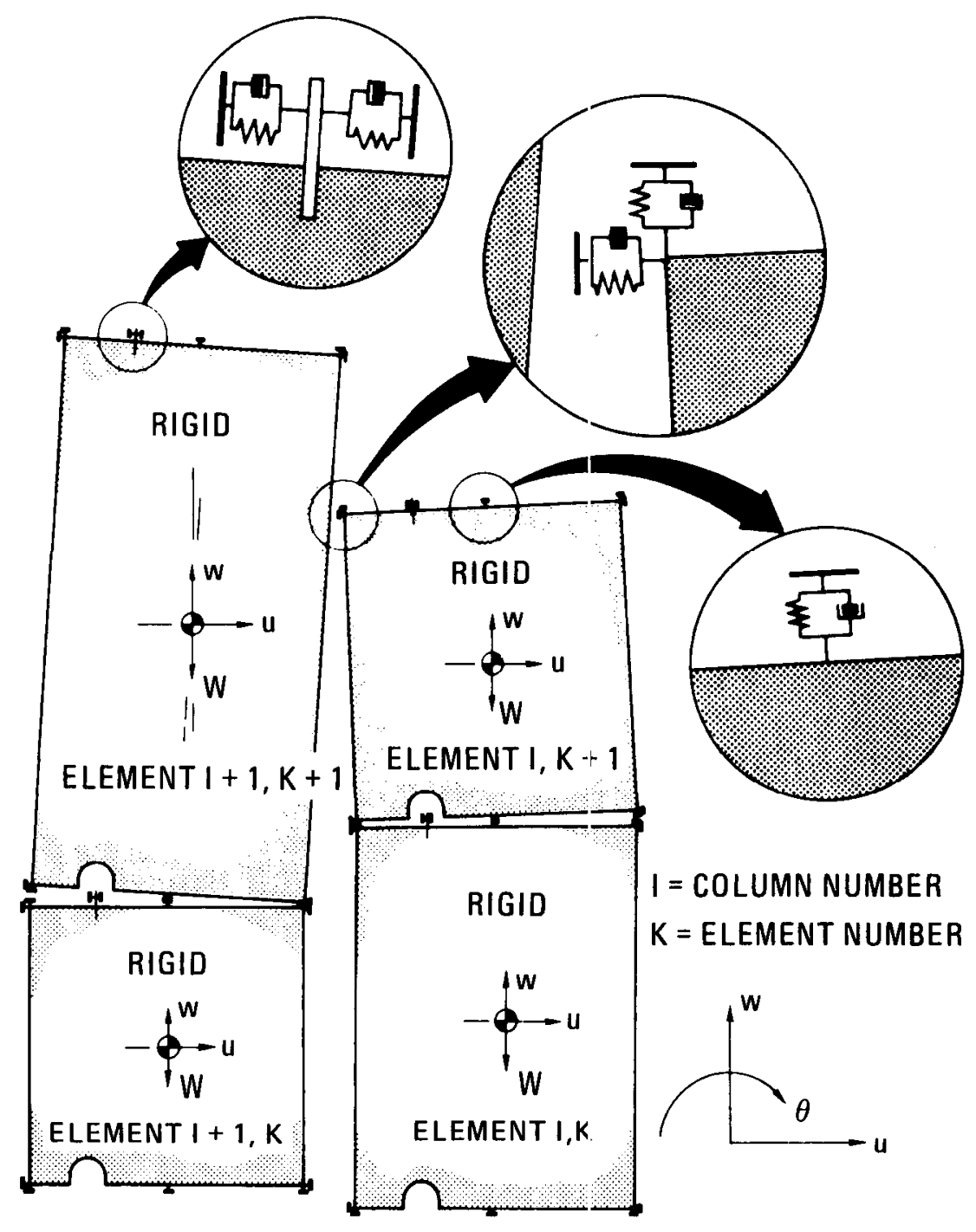

Fig. 17. MCOCO model 
constant and damping coefficient in CRUNCH and MCOCO. In Fig. 18, the free motion of a full-scale graphite element on a fixed base is plotted against time for both test and analysis and agreement is quite good. The vertical corner spring stiffness was not based on contact time. Vertical frequency responses of the column is important to the overall core motion and is most accurately reproduced by using static spring constant. Static values, however, require excessive computational costs.

Vertical column resonance must be about the same with reduced spring constants as with static values. Therefore, element spring rates in the vertical direction were set to values approximately equal to the horizontal spring constants which lowered resonance only $4 \%$.

\section{COMPARISON OF FREQUENCY RESPONSE}

Resonance characteristics produced by $\mathrm{CRUNCH}-1 \mathrm{D}$ and $\mathrm{CRUNCH}-2 \mathrm{D}$ for the $1 / 5$ scale, full-array core are presented in Fig. 19. Midheight spring pack loads versus excitation frequency were utilized to define resonance for the CRUNCH codes. Also shown on the figure are spring pack loads resulting from a sinusoidal sweep with MCOCO. It should be noted that resonance occurred at 3.6 to 3.7 Hz for the CRUNCH-1D and CRUNCH-2D core models. MCOCO, on the other hand, was exercised from 3.3 to $4.2 \mathrm{~Hz}$ and resonance was not produced. A $0.5 \mathrm{~g}$ sinusoidal sweep was employed for boundary excitation. Sweep rates were 0.5 decades/min for both CRUNCH codes and 1.0 decade/min for MCOCO. The boundary contained linear spring packs with a single spring rate of $800 \mathrm{lb} / \mathrm{in}$.

\subsection{Sweep Rate}

In the previous section, it was stated that two (different) values of sweep rate were used for the CRUNCH and MCOCO programs ( 0.5 and 1.0 decades/ min, respectively). The higher value was used in MCOCO to reduce cost and improve computer usage. Real time required to execute a sinusoidal sweep is defined by the equation

$$
t=\frac{60}{\rho} \log \left(\omega_{2} / \omega_{1}\right)
$$




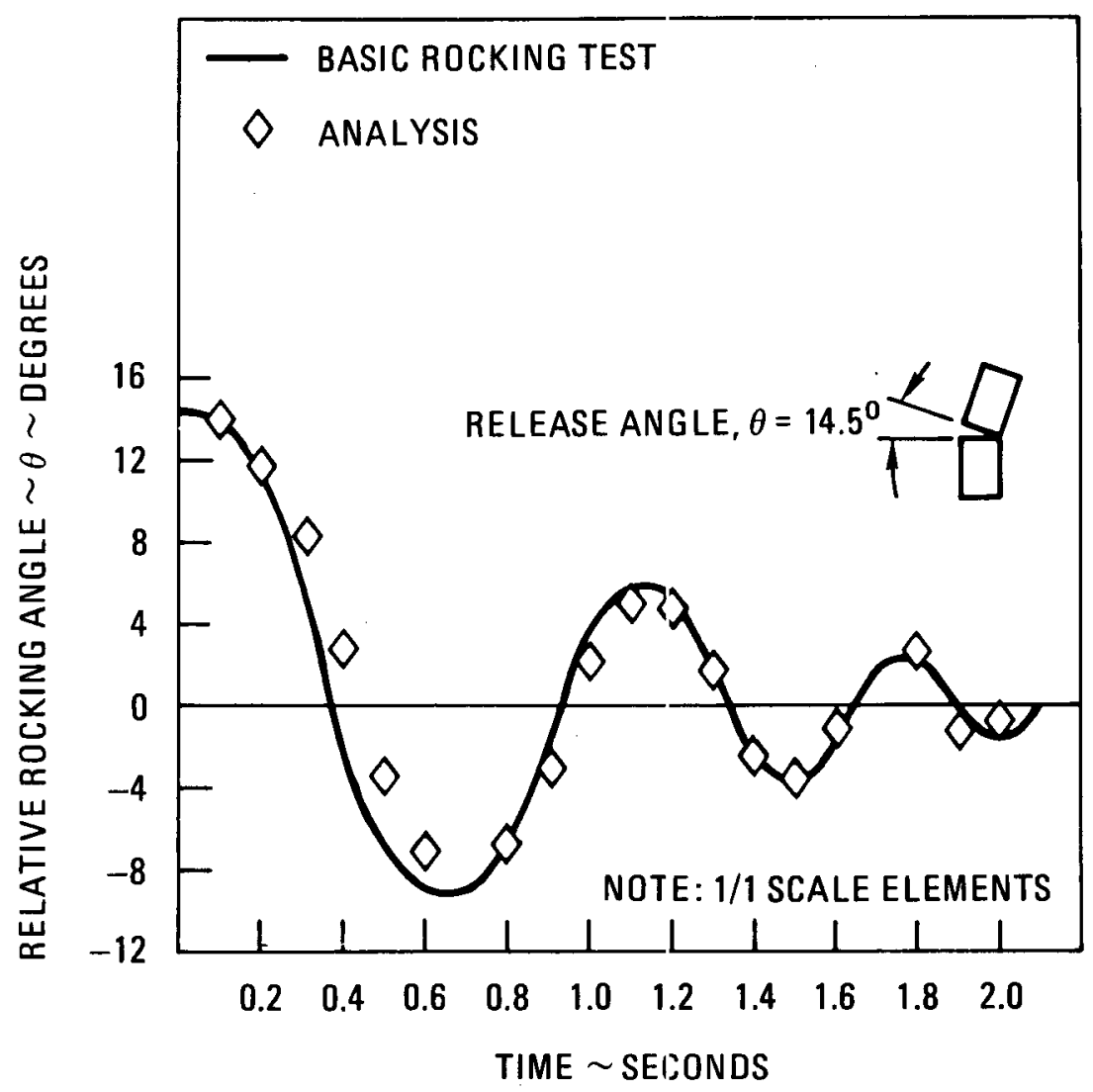

Fig. 18. Rocking angle time history 


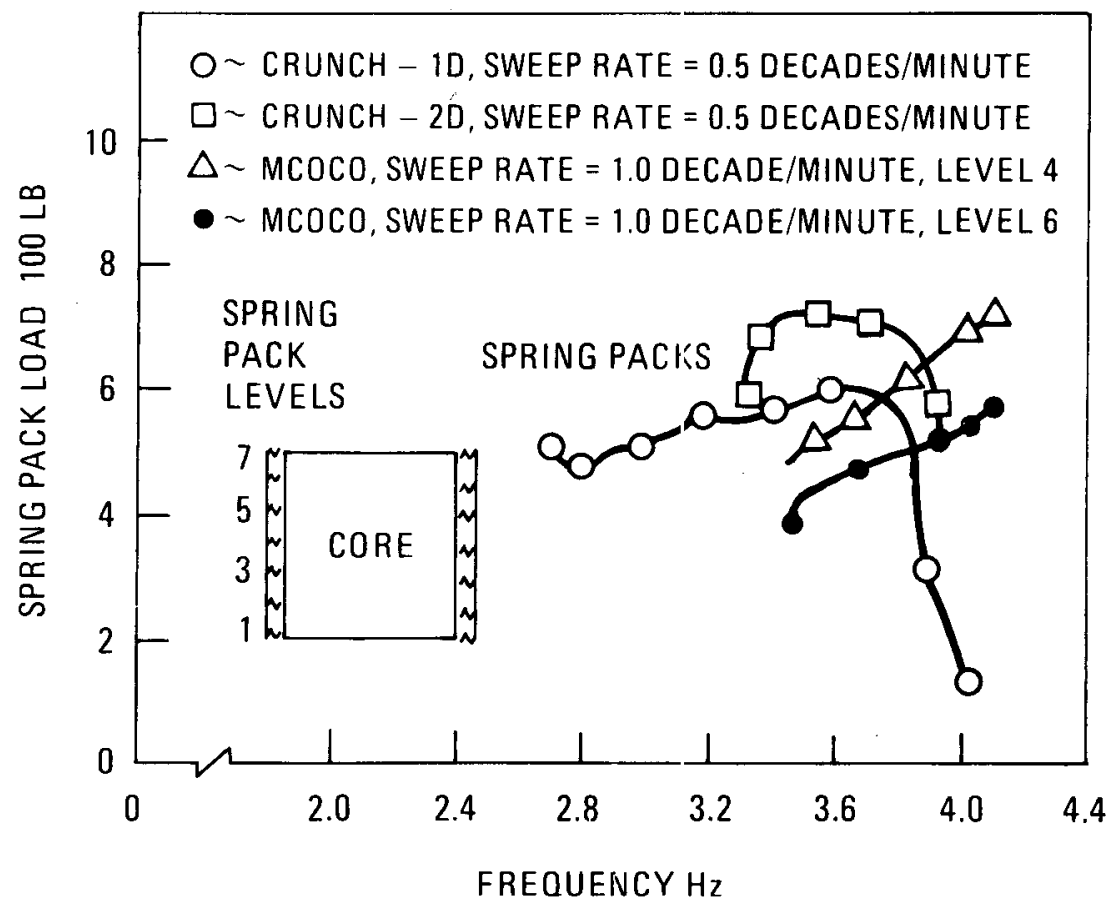

Fig. 19. Resonance characteristics 
where $t$ is the real time in seconds, $\rho$ is sweep rate in decades/min, and $\omega_{1}$ and $\omega_{2}$ are initial and final sweep frequencies $(\mathrm{Hz})$, respectively. Increasing the sweep rate by 2.0 reduces run time by one-half. Figure 20 provides the justification for utilizing the 1.0 decade/min sweep rate. Midheight spring pack load versus frequency from CRUNCH-1D is plotted for both sweep rates. There is very little change in the load macinitudes, and no perceivable change in resonance occurs. MCOCO behaves in a similar fashion.

\subsection{Frequency Response}

Frequency response produced by the three codes is presented in Fig. 19. The three models of the full core are showr in Figs. 2, 6, and 7. Common input was utilized where appropriate. Differences in resonance produced by MCOCO and the CRUNCH codes is thought to stem primarily from core damping. CRUNCH-1D and CRUNCH-2D both employ theoretical input values of column and core support floor to ground damping. It has been shown with $\mathrm{CRUNCH}-10$ that a variation in these parameters can modify the resonant frequency by $40 \%$. MCOCO, however, uses on ly localized damping which produced resonance at a value somewhat different than values generated by CRUNCH. Damping sensitivity and the discrepancy between CRUNCH and MCOCO resonance are currently under investigation.

\subsection{MCOCO Core Motion Characteristics}

Core and boundary motion from the MCOCO code may be plotted as shown in Fig. 21. The deformed shape of the 1/5-scale full array core model during a $3.5-\mathrm{Hz}$ 0.5-g sinusoidal dwell boundary excitation is depicted. It can be seen that all fuel columns are essentially deformed the same amount, and illustrates rather strikingly the core lumping characteristic discussed previously. Again, it should be noted that this phenomenon (lumping) was also observed during tests.

\section{FUTURE DEVELOPMENT}

Development of the computer codes is complete. However, improvements and minor modifications to the models are continuing in order to achieve better 


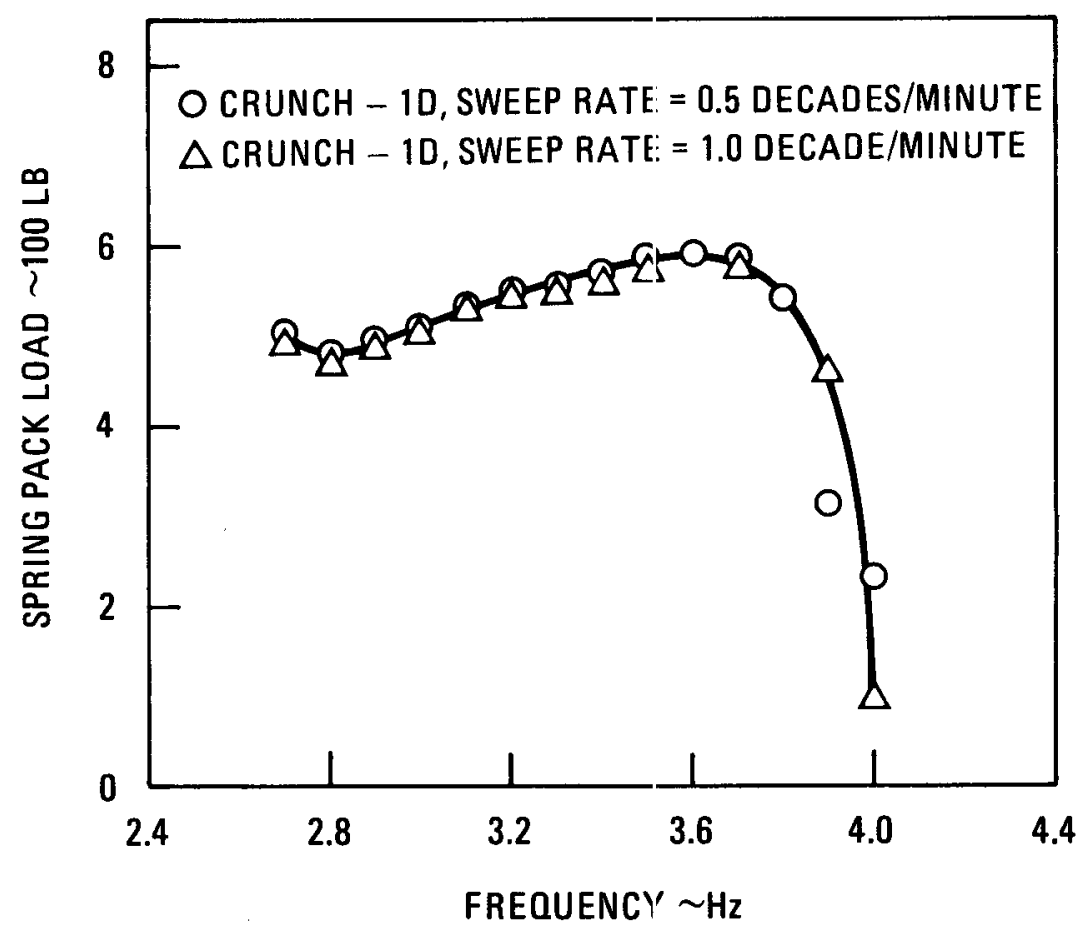

Fig. 20. Effect of sinusoidal sweep rate 


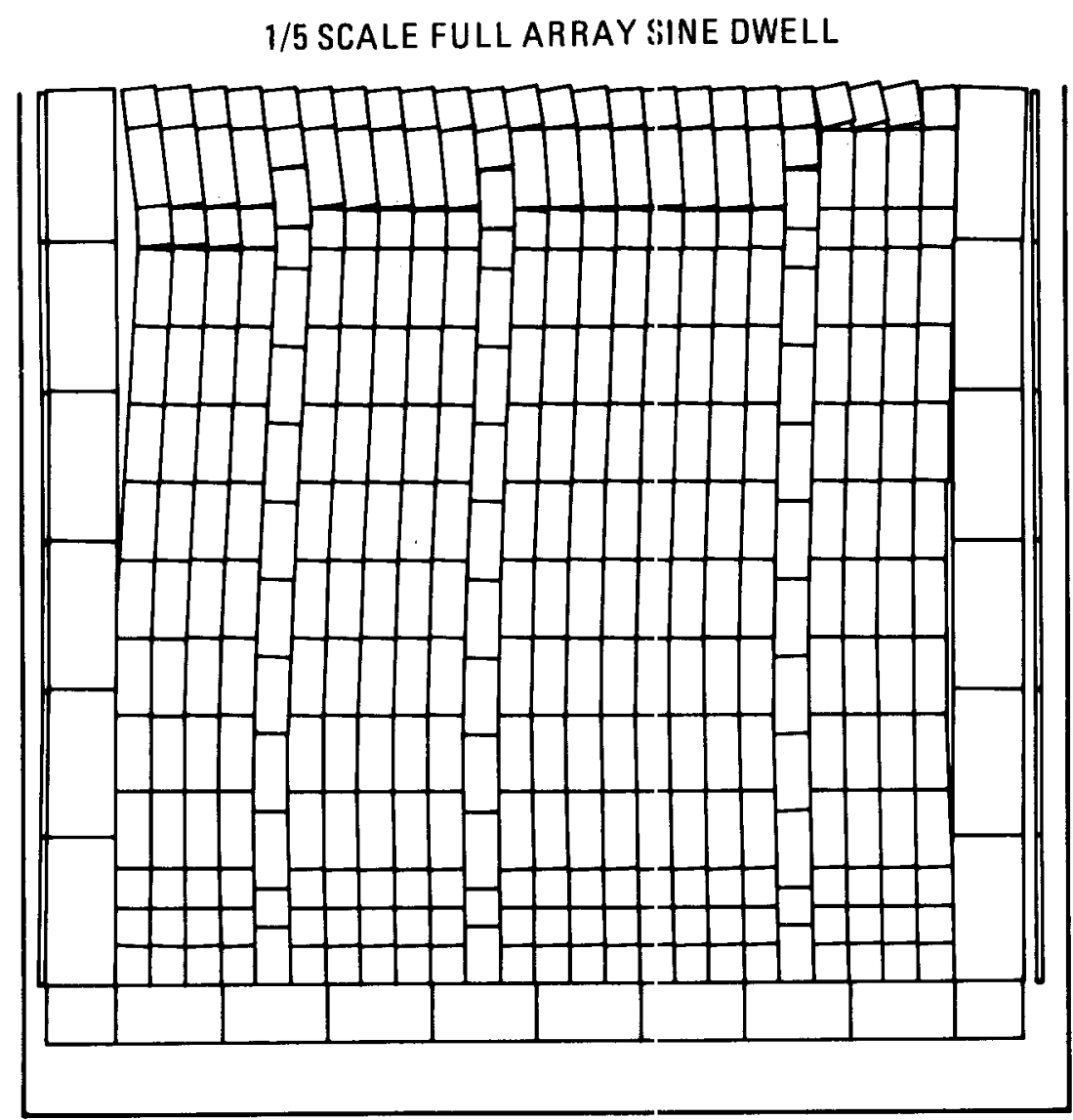

MCOCO MODEL DEFORMIED SHAPE

Fig. 21. MCOCO displacement plot 
correlation with experiments, greater efficiency, and reduced run costs. The CRUNCH-1D code, which is inexpensive to run, has been executed the most often. The CRUNCH-2D and MCOCO codes, on the other hand, are very costly. One MCOCO run for the 1/5-scale full array core requires up to $25 \mathrm{hr}$ of computer time for $3 \mathrm{sec}$ of real time; $\mathrm{CRUNCH}-2 \mathrm{D}$ is somewhat less expensive. The major requirement at present is to reduce computational cost, especially for MCOCO. One technique being considered is the use of an array processor. The potential reduction in run time and run cost may allow full utilization of MCOCO and CRUNCH-2D which would result in improved core models and more accurate design analysis. The MCOCO core model needs additional development for internal friction and damping produced during core motion. Present models account only for local energy loss which is significantly less than the measured values. Conservatism is therefore introduced into design analysis.

- Other aspects of code modeling also require improvement. Examples are the column spring in CRUNCH-1D and CRUNCH-2D. These represent column breakaway characteristics and coupling between the core and the effective core support floor mass. Of great interest also is the "rigid link" effect of the reflector elements. This effect tends to act as a "solid" ring in circular compression but separates in tension. Current models of the ring link may require improvements. However, present codes provide significant analytical capability and a comprehensive approach to the motion analysis of the large HTGR core. 


\section{REFERENCES}

1. Neylan, A. J., "Design Development of the HTGR Core and its Support Structure-Seismic Considerations," Second International Conference on Structural Mechanics in Reactor Technology, Berlin, Germany, 14 Sept. 1973, Vol. 6B.

2. 0lsen, B. E., A. J. Neylan and W. Gorholt, "Seismic Test on a One-Fifth Scale HTGR Core Model," Nuclear Engineering and Design 36, No. 3, (1976) pp. 355-666.

3. Rakowski, J.E. and B. E. 01sen, "Measuring the Seismic Response of an HTGR Core Model," Fourth International Conference on Structural Mechanics in Reactor Technology, San Francisco, California, 15-19 August 1977.

4. Rickard, N. D., "CRUNCH-1D. A Computer Program for Seismic Analys is of the HTGR Core," General Atomic Report GA-A14120, March 1977.

5. Tow, D., "CRUNCH-2D. A Two-Dimensional Computer Program for Seismic Analysis of the HTGR Core," General Atomic Report, GA-14765, February 1978.

6. Thompson, R. W., "MCOCO. A Computer Program for Seismic Analys is of the HTGR Core," General Atomic Report GA-A14764, Apri1 1978.

7. Rodkin, S. M. and B. E. 01sen, "HTGR Fuel Element Collision Dynamics Test Program," General Atomic Report GA-A14728, September 1978. 